\title{
COVID 19 - A Metamorphosis In Indian Higher Education Institutions With Technology Infused Learning
}

\author{
Veena Shenoy ${ }^{1}$, Rashmi Uchil ${ }^{2}$, Jacob Alexander ${ }^{3}$, Sheetal Mahendher ${ }^{4}$ \\ ${ }^{1}$ Assistant Professor, ISBR Business School, and Research Scholar NITK Surathkal Mangalore, India \\ ${ }^{2}$ Assistant Professor NITK Surathkal Mangalore, India \\ ${ }^{3}$ Director, The Oxford College of Business Management, Bangalore, India \\ ${ }^{4}$ Associate Professor and HOD- Quantitative Techniques \& Analytics, ISBR Business School, India \\ email: ${ }^{1}$ veena3172@gmail.com
}

\begin{abstract}
Change is crucial for institutions in a growing and highly competitive environment. COVID 19 pandemic made a revolution in Indian higher education institutions by adapting to technology in the classroom. The purpose of this paper is to understand the technology adoption, teaching, and learning process towards virtual classrooms during Lockdown due to COVID 19, India. Inductive reasoning used in this study and qualitative research methods is used to collect the data from faculties and students associated with the Higher education institutions in Bangalore, India. The finding of the study suggests that during the lockdown period, faculty have undergone the process of technology adoption, whereas students are involved with various online modes of learning. This study is confined to the positive side of COVID 19 and Change in the education sector by adapting to technology and engaging students with various virtual sessions. The current study is limited to the sample frame of 50 from faculty and 48 from students from the Higher education institutions at Bangalore, India, hence finding of this study cannot be generalized for entire India. The emotions and perceptions of faculty and students towards the usage of technology may differ based on the location. There was lots of resistance in teaching fraternity towards adapting to technology. We intended to understand the emotions of students and faculty and crisis based change and not on creating hype for technology adaption or virtual classrooms. Moreover, the focus has to be given on a hybrid system of education. That helps in sustainability and education ambidexterity.
\end{abstract}

Keywords: COVID 19, Lockdown, Technology Adaption, Teaching, Learning, Indian Higher Education Institutions, sustainability, ambidexterity.

\section{Introduction}

COVID 19 pandemic has created stress among academicians and students in higher education institutions. During these situations, there is a transformation in the classroom activities from traditional mode to online modes. The new environment and context have created a new way of teaching and learning and student engagement (Liu, 2020). In these scenarios, drastically moving from face to face to online teaching and learning (Charles Hodges, 2020) for both faculty and students have created dissonance and immediately was not ready for an emergency online learning (Nese, 2020); hence this was the major challenge for higher education institutions. This situation presence need for qualitative and empirical research in the field of teaching and learning (Lee, 2020), student engagements, and faculty and students' perspective towards the switch of technology in Indian higher education institutions. Evidence suggests that the use of technology in the teaching and learning process may promote a positive learning environment and contribute to students' and faculty's success (Spencer, 2020). Successful student learning depends upon individual differences in interactions, motivation, cognition, behavior, and emotion (Kim, 2019). The growing demographical diversity of students in higher education is evidenced and documented. Their expectations from educational institutions have changed compared to early-stage learning. They expect more and more from institutions and faculty in terms of teaching and learning and placement activities. Hence 
there is a need to explore the study in understanding the perception of faculty and students towards technology adoption during COVID 19 lockdown and how it has influenced the teaching-learning in student engagement, and faculty involvement. Moreover, these disruptions are a time to rethink and reflect on the educational sector. Thus technology intervention has a crucial role in educating future generations.

\section{This study demonstrates the following research question:}

- What is the Metamorphosis in Indian Higher Education Institutions with Technology Infused Learning from faculty and students' perspective?

Based on our research question, the research objective is developed.

To understand the Metamorphosis in Indian Higher Education Institutions with Technology Infused Learning from faculty and students perspective

\section{Theoretical Background :}

This study is based on Kurt Lewin's model of change (Kariel, 1956). The theory is widely used in the field of social science and richly used in implementing change in organizations (Gershwin, 1994). Earlier research has related this theory in processbased changes adapted by the organization due to the situation and need-based (Botelho, 2013). According to Lewin, the process of change is based on three levels - unfreeze, move, and refreeze. Unfreeze is the first stage, that is the foundation in preparing own-self to accept the occurring changes. In the second level, it is moving with the change and understanding the need for the change with usage. The third level is about the new change that is successfully absorbed, implemented, and adapted by the environment and organization.

Application of Kurt Lewin's model of change in Technology Adoption :
During COVID 19 pandemic Lockdown, Higher education institutions have changed the way it used to work (Schein, Kurt Lewin's change theory in the field and in the classroom: Notes toward a model of managed learning, 1996). The process of change was inevitable and revolving (Lewin, 1977). The Prime Minister of India has announced the national Lockdown 1.0 for 21 days and later Lockdown 2.0 for 20 days. The education system in India had a huge impact on these lockdowns and it was a crisis-driven situation. The moving of the complete system to a new concept was daunting specifically about its adaptability, training faculty for the systemic change, student engagement, and other aspects (Hussain, 2018).

However, despite the challenges, most of the Indian higher education institutions had adapted the technology for teaching and learning (Cummings, 2016). Moreover, some institutions started implementing the new system in place from Lockdown 1.0 and the other few started in Lockdown 2.0. The situation was crucial in influencing the behavior of faculty (Saldern, 1986) and students due to the switch-over from regular classroom sessions to online classrooms (Benne, 1976). Initially, there was a resistance to adaptability as compared with the regular classroom sessions. The leadership in various management institutions have adopted the model and gave instructions to faculty to adapt to the technology-driven system. Thus, we have applied Kurt Lewin's model in the process of adopting technology (Kurosawa, 1995). The first stage was unfreezing, more of understanding the behaviors, attitude, usage, benefits, challenges in virtual learning from both the faculty and students. The second phase was about adapting to the change and understanding the need and the necessity of it, and lastly, students started liking virtual classrooms and thereby refreeze the same. Hence they 
have adopted the change by completely engaging the newly developed system.

\section{Literature Review}

\section{Indian Higher Education}

Indian Higher education is in the world's third-largest in terms of students (Saini, 2019). The Education systems determine the economic success of the state, and most of the developed countries are found to be high in literacy rate and falls under the educated class. India's higher education systems have seen the change of increase in the number of universities, institutions, colleges since postindependence (Sheikh, 2017). The basic phrase "knowledge is power" goes well as the more knowledge we acquire, the more empowered we will. The various challenges in higher education are concerned with creating stakeholders' experience, engagement, involvement, and satisfaction (Alase, 2017) and other attributes such as quality, infrastructure, equity, accreditation, research, and innovation.

Amid all these existing challenges, COVID 19 appears to be more threatening to the education system as adapting technology and virtual classrooms are something majority institutions lack. Despite the challenges of technology adoption, this lockdown turns out to be an opportunity for teaching fraternity and students to explore new technology and means of the virtual classroom. There is various literature on digitalization in Indian higher education (Romainville, 1999), but that was process-based and not transformative. The hybrid system of education is always better for both faculty and students. However, due to crisis, it is a disruption in the Indian higher education, moving from regular classroom sessions to virtual online classrooms. Various bodies and authorities such as MHRD ( Ministry of Humann Resources Development),
UGC ( University grant commission), AICTE ( All India Council for Technical Education), initiated various online portals for E-learning (Subba Rao, 2004) and created the opportunity for students and faculty for teaching and learning during this pandemic. Hence there is a need to turn to the technology embedded system in higher education and their scope to explore the study looking into the advancement of education institutions.

\section{Technology adoption}

The usage of technology (SchwartzBechet, 2012) and technology enablement (Rice, 2008) for teachers has shown a dramatic change and effectiveness. Moreover, it created positive faculty experience and student involvement. Millennials being techsavvy, get connected quickly with the advancement in technology. They carry different mindsets when it comes to technology and its usage. Initially, when the pandemic erupted it created dissonance in stakeholders' minds in higher educational institutions. From a student's perspective, adoption of technology was much acceptable as for the first time they completely switched to the online mode of learning. However, for the faculty, it created anxiety, fear, and tension in reaching out to students, and their involvement was questioned due to technical issues mainly because of dispersed geographical situations. With more and more active involvement in teaching, technology usage is convenient with a sound network, but safety and security will still be a concern (Serap Gorucu, 2018). Technology adaption is inseparable as there was no option left due to pandemic and students expressed positive emotions towards technology integration and performance (Kohen, 2019).

\section{Teaching and Learning}

The Insititute of higher education has faced an acute crisis in the entire period of 
its existence. Changes that otherwise take many years are now forced

upon the teaching fraternity in months. Classrooms have shifted from regular to online. Faculties are making pedagogical changes to adapt to the online classroom and make students comfortable (Laura Thomas, 2020). There had always been a discussion on teaching-learning in higher education, whether it should be studentcentric or faculty centric. Due to the pandemic, teaching and learning were switched to virtual mode. Most of the colleges in Bangalore, India uses Zoom, WebX, Google Hangouts, Skype meetings, Google meet, Avaya, youtube, and google classroom for assignments. The engagement level of students was found higher than in regular classrooms. The changes brought many in the teaching fraternity to think that as it is a new phenomenon student involvement is higher. Faculty are working longer hours than a regular schedule (Rebecca Allen,

2020) and they are performing different roles such as guide, mentor, counselor, information provider, role model, and problem solver. There was a challenge for novice teachers to cope up and adapt to technology. Nevertheless, they were also doing a great job with the opportunities provided by management and policymakers. Students-faculty bonding has increased, and they often connect with the new model in teaching and learning (Björn Sjögren, 2020).

\section{Methodology and Methods}

The study is based on qualitative data collected from 30 instructors teaching in higher education institutions and 52 students pursuing their higher studies in Bangalore, India. A telephonic interview was conducted among respondents. Faculty and students have been asked open-ended questions based on four categories. The study is to examine the perception of faculty and students towards Technology adaption, teaching and learning, student engagement, and faculty experience towards virtual classrooms during COVID19- Lockdown. The following are the opinions shared by faculty and students based on their experience of the virtual classroom, teaching and learning, and student engagement and faculty experience. (rewrite it)

\section{Discussion}

The following are the responses from faculty towards technology adoption, teaching and learning, student engagement, and faculty experience.

\section{COVID 19: Technology Adaption}

People resist change without understanding the need and importance of it, and when a situation arises, all should adapt to change willingly and unwillingly. It was the situation that occurred to the teaching fraternity too. Indian higher education institution has used various pedagogy for innovation, development, and engagement of students. Many faculties had resisted the change when they had been asked to take virtual classes for students. The management of the institutions provided a couple of training sessions to ensure that faculty will not face any difficulties in the course of teaching. As everything is a mindset, the faculty has to change their mindset towards the virtual classroom and adopt technology for the betterment of students.

With the adaption of technology, faculty were using virtual modes for meetings, guest sessions, faculty development programs, students mentoring, online club activities, and various competitions for faculty and students. Technology has revolutionized the Indian higher education system and will be used extensively.

\section{COVID 19: Teaching and learning}

Teaching and learning are always in demand, and when faculty heard about Lockdown due to COVID 19, it was a 
challenge for faculty to look this as an opportunity to go for virtual classrooms, virtual learning, and teaching. With the crisis, there is a full adaption of technology in teaching; learning in higher education institutions in Bangalore. The higher educational institutions in Bangalore have opted for online classes. The tools used by faculty during Lockdown for teaching and learning through online modes are Zoom, WebX, Google Hangouts, Skype meets up, Google classrooms, LMS, ICT, YouTube. Many institutions conducted Faculty development programs online to gear up the positivity among faculty during the crisis. Faculty feel there is no much difference between online and offline sessions as they can share PPT, play videos, and use board and marker as regular classrooms. One exciting part, one of the respondents, was handling an analytics course for PGDM students, and even she can run all the codes online, and students were very positive towards the learning and course. Furthermore, faculty have also done online role-play, group presentations, guest sessions by experts in the field, and CEO talk online. It has created a revolution in the higher education institutions and proved the hybrid system of teaching through offline and online mode.

\section{COVID 19: Students Engagement}

Student engagement is a challenge today, tomorrow, whether offline or online (Harper, 2016). Initially, faculties had lots of dissonance towards student's engagement during a lockdown. When faculty started taking sessions online, they were shocked to see students' attendance is 20 times better than regular class sessions, and it was almost 100 percent attendance while engaging them virtually. There is various initiative from the Ministry of Human Resources Management (MHRD), an offering of free Swayam courses. Many institutions subscribed to online free courses for students during the lockdown period. ELibrary sources and EBooks' have been shared with students. Apart from regular virtual class engagement, there are various initiatives taken for students' engagement. Prof. Shenoy, ISBR Business School said, the ISBR HR club, Convergence Namma club has taken the initiative of collaborating for coffee online and share gratitude every Friday at $5 \mathrm{pm}$ during the Lockdown period. It was a form where students will have social interaction with each other, as humans are social animals they need to collaborate, exchange their views, and experience with each other whether they are offline or online. Hence this was the forum created to exchange their ideas and give gratitude. Moreover, she also added that Club has also proposed for a Case writing competition for students and faculty on COVID19: Lockdown, HR perspectives.

\section{COVID 19: Faculty Experience}

In India, academicians are used to conducting classes in a physical, visual setting. There was a part of programs that calls for on-line teaching which is more evident at the executive and Ph.D. levels. However, to alter from a physical setting to on-line was more like a trauma for average institutions, even though many institutions have undergone some part of on-line teaching in the past. At the faculty level, it was not the inhibition of the sudden change but more to do with the systemic change as the lockdown happened at a lightning pace without any implementation time. But with the intervention of the leadership team, the lacuna was addressed at a rapid pace. Thus, faculty embellished their teaching skills in quick succession and transformed the physical classroom into virtual settings. After adapting to the new system, it was now time to transform the same learning to their students and that was a challenging task at the initial stages. However, over time Faculty members observed that there was a change in the 
student's behavior when they switched to online learning. Students who were Shy and not opening up in a regular classroom started with interacting in online classrooms. Moreover, student's involvement was much higher, and they started looking for solutions or actively search for their answers online rather than passively dependent on their faculty. Furthermore, they also observed that this online learning made them think more and also helped students develop their critical thinking and questioning skills (McKnight, 2016). Thus it was a win-win situation for all and blessings in disguise.

The following are the responses from students towards technology adoption, learning, student engagement, and students' experience.

\subsubsection{Technology Adaptions:}

The pandemic of COVID 19 has been forced to adopt technology worldwide in the education sector. As a new generation, students are already enjoying the latest technology. Despite that, online studies were new for most of the students. Students were terrified with the virtual classes' announcement in their Higher education institutes due to Lockdown. Many international students were unable to go to their respective countries for their regular courses due to COVID 19 pandemic. To make students comfortable, they were provided the proper guidelines to join the online classes through emails and telephone medium. Teachers' flexibility and cooperation in the management of education institute students are being able to cope with the change management to continue their studies. Technology adaption in higher education institutes for continuity, of course in Lockdown, acted as bliss, which was ever imagined to be so smooth in enriching students' skills and knowledge was the critical opinion of the students from all Nepal, India, and Australia. Students are advised to use virtual modes for meetings, regular classes, and online activities, which can be taken as an example of the adaption of technology. Technology widely enforced the students to accept and experience multiple education procedures due to COVID 19 lockdown.

\subsubsection{Learning:}

Learning from different mediums that also in a pandemic is undoubtedly very hard to accept by the students. Initially, the student was very panicked and was not able to cope with online classes. There were not being able to set their mind in regards to the teaching style of teachers and classroom activities. After the second week of the online session, students believe that there is no more difference between online and classroom sessions as PPT, play videos are available, and even teachers use board and marker as they used in their regular classrooms in practical subjects. One on the respondent admits that online classes are making her feel secure as well as it saves her time, and she can give her traveling time to her one and 6 month old child. To enrich the knowledge from virtual classes, teachers post online classes recording in their Moodle so that they can listen to the lecture repeatedly if they get confused. Students facing network issues, take video recordings as an additional advantage of virtual class because there is no smooth internet service. Hence, the overall perspective of students is positive towards the online class despite all technical issues regarding the internet network in Bangalore, India.

\subsubsection{Students Engagements:}

Students in virtual classrooms were feeling safer to attend the class, as this situation is created due to a communicable disease called COVID 19. The class from any corner of the world through their mobile as well as laptop, computers, and tabs. Therefore, they were delighted to get engaged through those gadgets. As this is a very new experience for most of the 
students in India, they try to give more concentrations on what is going on in online classes and try to interact. As the Ministry of Human Resources Management (MHRD), of India, several higher education institutes have offered several initiatives, and free courses till this COVID 19 pandemic students are being stress-free and happy to be engaged in online classes. The students are facilitated with study materials through E-library and Ebooks, which is giving them a resolution to their problems. A platform for case writing competition and sharing their gratitude is making them more active regardless of fear of COVID 19. Besides, this participating in the discussion forum is helping them to share their knowledge with the class and improve their knowledge, said most of the respondents. Students can connect and exchanges their views openly despite Lockdown, which is very important for human beings. Hence, online classes can succeed in enhancing student engagement in high ration than offline classes.

\subsubsection{Students Experience:}

Students were perplexed with the scenario and the change management and higher education institute behavior concerning continue courses through virtual classes. After attending virtual classes, students experience positive vibes, and they started loving it. In the word of respondents, "it is our first experience to study online, It was very excited to attend the class from home, though am getting difficulties with online exams, I am enjoying my classes." In addition to this other respondents, "I am very much glad to get experienced in online learning, more than that I am happy to watch the class video whenever I am confused with the topic and miss the lecture due to network problem." Respondents from rural Bangalore, "it was the first time I am learning online; initially, I thought it is going to be difficult, and my experience is opposite and am happy to learn online than offline."
Respondents from South Bangalore, "Online classes saved our life, and gave new experience along with excitement." Therefore, all students are pleased with technology adoption, teaching, and learning methods adopted in higher education institutions in India

\section{Finding and Results}

This study is based on Kurt Lewin's model of change. The Pandemic has disrupted Indian higher education, as there was lots of resistance among the teaching fraternity towards adapting to technology. The situation has driven faculty at higher education institutions in Bangalore to use technology tools in their teaching and started taking virtual classes, Virtual engagement of students seemed better than regular classrooms, and attendance clocked at almost 100 percent. Hence, educationalists, policy makers, and leaders have taken this innovation to the next level by implementing it in other undergraduate programs. Therefore the study is not about creating hype for virtual classrooms but intends to create and carry the innovation so that all the stakeholders benefit from it.

\section{Limitations and further Scope for Study}

This study is confined to the positive side of COVID 19 and Change in the education sector by adapting to technology, teaching, and learning and engaging students with various virtual sessions. The current study is limited to the sample frame of 20faculty from Higher education institutions in Bangalore, India, hence finding of this study cannot be generalized for entire India. The emotions and perceptions of faculty towards the usage of technology and experience are different for different users. As all of us know, we are not the United States when it comes to data consumption and usage. In India, we have lots of technical issues when it comes to data consumption and usage. Future researchers considered this as a research gap and focused on various other modes to 
collect through empirical support and analysis for better results.

\section{Conclusions}

This study helped us to understand the perception of faculty and students towards COVID 19 Lockdown and towards technology adaption and teaching and learning in higher education institutions as this study is confined to the positive side of the COVID 19 and opportunities in higher education institutions. We intended to understand the emotions of students and faculty and crisis based change and not on creating hype for technology adaption or virtual classrooms. Moreover, the focus has to be given on a hybrid system of education. That helps in sustainability and education ambidexterity. It can act as a stepping stone for policymakers in educational institutions to look into these attributes and to implement similar strategies during crises for the betterment of the institutions.

\section{Works Cited}

[1] Alase, A. (2017). The interpretative phenomenological analysis (IPA): a guide to a good qualitative research approach. International Journal of Education and Literacy Studies, Vol. 5 No. 2, pp. 9-19.

[2] Benne, K. D. (1976). The processes of re-education: An assessment of Kurt Lewin's views. Group \& Organization Studies, 1(1), 26-42.

[3] Björn Sjögren, R. T. (2020). Bystander behavior in peer victimization: moral disengagement, defender self-efficacy, and studentteacher relationship quality. Research Papers in Education, DOI: 10.1080/02671522.202.

[4] Botelho, M. D. (2013). Kurt Lewin's model of change revisited in a Brazilian Higher Education context. UFRA.

[5] Charles Hodges, S. M. (2020). The Difference Between Emergency
Remote Teaching and Online Learning. Educause Review.

[6] Cummings, S. B. (2016). Unfreezing change as three steps: Rethinking Kurt Lewin's legacy for change management. Human Relations, 69(1), 33-60.

[7] Gershwin, M. C. (1994). What Workplace Education Programs Need To Know about Behavioral Change: Tapping the Work of Kurt Lewin. ERIC.

[8] Harper, B. \&. (2016). One-to-One Technology in $\mathrm{K}-12$ Classrooms: A Review of the Literature From 2004 Through 2014. Journal of Research on Technology in Education, 48(2), 129-142.

DOI:10.1080/15391523.2016.11465 64.

[9] Hussain, S. T. (2018). Kurt Lewin's change model: A critical review of the role of leadership and employee involvement in organizational change. Journal of Innovation \& Knowledge, 3(3), 123-127.

[10] Kariel, H. S. (1956). Democracy unlimited: Kurt Lewin's field theory. American Journal of Sociology, 62(3), 280-289.

[11] Kim, M. K. (2019). The role of expressed emotions in online discussions. Journal of Research on Technology in Education, 1-18. DOI:10.1080/15391523.2019.16978 61.

[12] Kohen, Z. (2019). Informed integration of IWB technology, incorporated with exposure to varied mathematics problem-solving skills: its effect on students' real-time emotions. International Journal of Mathematical Education in Science and Technology, 50:8, 1128-1151, DOI:

10.1080/0020739X.2018.1562119.

[13] Kurosawa, K. (1995). Process interactionism, process analysis, and self process: An extension of Kurt Lewin's approach to personality 
psychology. The Japanese Journal of Personality, 3(1), 66-93.

[14] Laura Thomas, B. R. (2020). Unpacking the dynamics of collegial networks in relation to beginning teachers' job attitudes. Research Papers in Education, DOI: 10.1080/02671522.202.

[15] Lee, C. K. (2020). Exploring the use of virtual reality by pre-service elementary teachers for teaching science in the elementary classroom. Journal of Research on Technology in Education, 1-15. DOI: $10.1080 / 15391523.2020 .17262$ 34.

[16] Lewin, M. A. (1977). Kurt Lewin's view of social psychology: The crisis of 1977 and the crisis of 1927. Personality and Social Psychology Bulletin, 3(2), 159-172.

[17] Liu, Q. Z. (2020). Categorizing teachers' gestures in classroom teaching: From the perspective of multiple representations. Social Semiotics.

[18] McKnight, K. O. (2016). Teaching in a Digital Age: How Educators Use Technology to Improve Student Learning. Journal of Research on Technology in Education, 48(3), 194-211. DOI:10.1080/15.

[19] Nese, R. N. (2020). Using stakeholder feedback to improve online professional development opportunities. Journal of Research on Technology in Education, 1-15. doi:10.1080/15391523.2020.172623 3.

[20] Rebecca Allen, A. B. (2020). New evidence on teachers' working hours in England. An empirical analysis of four datasets, . Research Papers in Education,

DOI: 10.1080/02671522.2020.1736616.

[21] Rice, M. J.-W. (2008). Preservice teachers' guide for learner-centered technology integration into instruction. Interactive Technology and Smart Education, Vol. 5 No. 2, pp.

103112.

https://doi.org/10.1108/1741.

[22] Romainville, M. (1999). Quality evaluation of teaching in higher education. Higher Education in Europe, Vol. 24 No. 3, pp. 415-424.

[23] Saini, D. \&. (2019). What drives research in higher education? An Indian context. Journal of Applied Research in Higher Education, DOI:10.1108/jarhe-07-2018-0157.

[24] Saldern, M. V. (1986). Kurt Lewin's influence on social-emotional climate research in Germany and the United States. In The Lewin Legacy. Springer, New York, NY, 30-39.

[25] Schein, E. H. (1996). Kurt Lewin's change theory in the field and the classroom: Notes toward a model of managed learning. Systems practice, 9(1), 27-47.

[26] Schein, E. H. (1999). Kurt Lewin's change theory in the field and the classroom: Notes toward a model of managed learning. Reflections: The SoL Journal, 1(1), 59-74.

[27] Schwartz-Bechet, B. a. (2012). Using Technology to Enhance Teacher Education. Emerald Group Publishing Limited, Bingley, pp. 235261. https://doi.org/10.1108/S20449968.

[28] Serap Gorucu, D. M. (2018). Technology Use Among Youth While Operating Farm Equipment. Journal of Agromedicine, 23:4, 305314 , DOI: 10.1080/1059924X.2018.1501450.

[29] Sheikh, Y. A. (2017). Higher Education in India: Challenges and Opportunities. Journal of Education and Practice, Vol.8, No.1, 2017.

[30] Spencer, R. S. (2020). Exploring Top Hat's Impact on Undergraduate Students' Belongingness, Engagement, and Self-Confidence: A Mixed Methods Study. Journal of Research on Technology in Education, 1-19. 
DOI:10.1080/15391523.2020.17229

77.

[31] Subba Rao, S. (2004). E-book technologies in education and India's readiness. Program: electronic library and information systems, Vol. 38 No. 4, pp 257267. https://doi.org/10.1108/00330330410 566097. 